\title{
Use of Camera-Trapping to Estimate Puma Density and Influencing Factors in Central Brazil
}

\begin{abstract}
NUNO NEGRÕES, ${ }^{1}$ Center for Environmental and Marine Studies, and Biology Department, Aveiro University, Campus Universitário de Santiago, 3810-193 Aveiro, Portugal; Department of Conservation Biology, Estación Biológica de Doñana CSIC, Calle Americo Vespucio s/n, 41092, Spain

PEDRO SARMENTO, Center for Environmental and Marine Studies, and Biology Department, Aveiro University, Campus Universitário de Santiago, 3810-193 Aveiro, Portugal

JOANA CRUZ, Terra e Tudo, Consultoria e Gestão de Recursos Naturais, Unipessoal Lda. Quinta da Rebolosa, EM 566, 6090-000 Aranhas, Portugal

CATARINA EIRA, Center for Environmental and Marine Studies, and Biology Department, Aveiro University, Campus Universitário de Santiago, 3810-193 Aveiro, Portugal

ELOY REVILLA, Department of Conservation Biology, Estación Biologica de Doñana CSIC, Calle Americo Vespucio s/n, 41092, Spain

CARLOS FONSECA, Center for Environmental and Marine Studies, and Biology Department, Aveiro University, Campus Universitário de Santiago, 3810-193 Aveiro, Portugal

RAHEL SOLLMANN, Jaguar Conservation Fund, Caixa-Postal: 193 GO-341 km 84, Zona Rural, Zip Code: 75.830-000 Mineiros, GO- Brazil; Leibniz Institute for Zoo and Wildlife Research, Alfred-Kowalke-Str. 17, 10315 Berlin, Germany

NATÁLIA M. TÔRRES, Jaguar Conservation Fund, Caixa-Postal: 193 GO-341 km 84, Zona Rural, Zip Code: 75.830-000 Mineiros, GO- Brazil MARIANA M. FURTADO, Jaguar Conservation Fund, Caixa-Postal: 193 GO-341 km 84, Zona Rural, Zip Code: 75.830-000 Mineiros, GO- Brazil ANAH T. A. JÁCOMO, Jaguar Conservation Fund, Caixa-Postal: 193 GO-341 km 84, Zona Rural, Zip Code: 75.830-000 Mineiros, GO- Brazil LEANDRO SILVEIRA, Jaguar Conservation Fund, Caixa-Postal: 193 GO-341 km 84, Zona Rural, Zip Code: 75.830-000 Mineiros, GO- Brazil
\end{abstract}

\begin{abstract}
We used remotely triggered cameras to collect data on Puma (Puma concolor) abundance and occupancy in an area of tropical forest in Brazil where the species' status is poorly known. To evaluate factors influencing puma occupancy we used data from 5 sampling campaigns in 3 consecutive years (2005 to 2007) and 2 seasons (wet and dry), at a state park and a private forest reserve. We estimated puma numbers and density for the 2007 sampling data by developing a standardized individual identification method. We based individual identification on 1) time-stable parameters (SP; physical features that do not change over time), and 2) time-variable parameters (VP; marks that could change over time such as scars and botfly marks). Following individual identification we established a capture-recapture history and analyzed it using closed population capture-mark-recapture models. Puma capture probability was influenced by camera placement (roads vs. trails), sampling year, and prey richness. Puma occupancy was positively associated with species richness and there was a correlation between relative puma and jaguar (Panthera onca) abundance. Identifications enabled us to generate 8 VP histories for each photographed flank, corresponding to 8 individuals. We estimated the sampled population at 9 pumas ( $\mathrm{SE}=1.03,95 \% \mathrm{CI}=8-10$ individuals) translating to a density of 3.40 pumas $/ 100 \mathrm{~km}^{2}$. Information collected using camera-traps can effectively be used to assess puma population size in tropical forests. As habitat progressively disappears and South American felines become more vulnerable, our results support the critical importance of private forest reserves for conservation.
\end{abstract}

KEY WORDS Amazon Basin, camera-trapping, CAPTURE software, density estimation, individual identification, private reserve, Puma concolor.

Although pumas (Puma concolor) are widespread throughout Central and South America, their status remains poorly known over most of their range south of the United States (Nowell and Jackson 1996, Sunquist and Sunquist 2002). Being a more adaptable species than the other large cat of the Americas, the jaguar (Panthera onca), the puma is more widely distributed over a larger range of habitats and altitudes (Eisenberg 1989, Redford and Eisenberg 1992, Laundré and Loxterman 2007). Despite the capacity of the puma to adapt to different environments and its generalist habits as a predator it is likely that numbers of pumas have decreased in recent years because of prey decline, habitat loss, and fragmentation (Pacheco et al. 2004, Kelly et al. 2008).

There is a considerable lack of information on puma density, particularly in dense tropical forest habitats of Central or South America (Kelly et al. 2008) and most

\footnotetext{
${ }^{1}$ E-mail: nunonegroes@gmail.com
}

density estimates have been produced by radiotracking studies, which are mostly based on small sample sizes. The puma is a Species of Least Concern although on-going massive habitat destruction in the neotropics may be a threat to survival of the species (Logan and Sweanor 2001, International Union for the Conservation of Nature [IUCN] et al. 2008). In Brazil the puma is considered Near Threatened but subspecies outside the Amazon Basin are categorized as Vulnerable (Machado et al. 2005). Abundance of pumas in the dense rainforest of the Amazon Basin is unclear (Nowell and Jackson 1996). Evaluation of the status of both local and regional populations and subsequent development of conservation action plans are crucial to puma conservation (Nowell and Jackson 1996, Kelly et al. 2008).

Recently, camera-trapping has been used to address a variety of questions concerning carnivore populations (Carbone et al. 2001, Trolle and Kery 2005). Cameratrapping is particularly useful when identification of individuals is possible. Together with appropriate mark- 


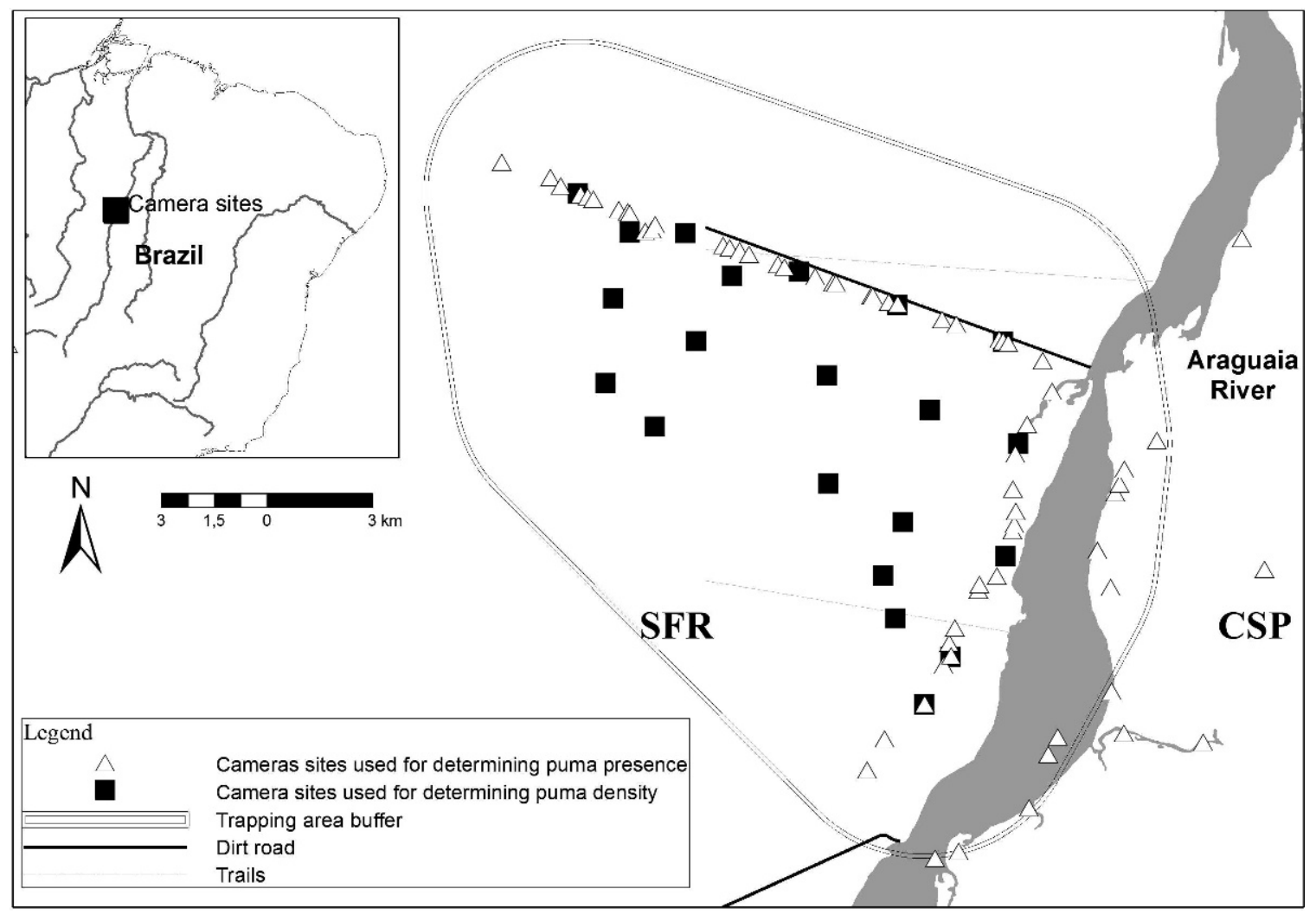

Figure 1. Study area showing the location of camera stations for 5 trapping campaigns in Cantão State Park (CSP) and Santa Fé Ranch (SFR) in Central Brazil for estimating puma presence and density (2005-2007).

recapture experimental design and analysis, camera-trapping allows estimating abundance and population density, while providing information on ranging behavior, activity patterns, dispersal, and migration (Karanth and Nichols 1998, Cutler and Swann 1999, Silveira et al. 2003).

However, pumas bear no conspicuous spot or stripe pattern, which may hinder individual identification. Kelly et al. (2008) assessed reliability of individual puma identification by photo-trapping using double-blind observer identifications. Capture histories based on those identifications and use of capture-recapture models allowed estimation of puma abundance across study sites according to different researchers (Rexstad and Burnham 1991, Kelly et al. 2008).

We estimated abundance and density of pumas in central Brazil by adapting the approach of Kelly et al. (2008) using remotely triggered cameras. Additionally, we used data from several camera-trapping campaigns to determine descriptive variables that can explain puma presence and occupancy at a local level. Finally, we examined data on puma capture success, activity pattern, and trail use.

\section{STUDY AREA}

We conducted our study in the middle Araguaia River basin, Brazil, at the Santa Fé Ranch (SFR) and Cantão State Park (CSP; Fig. 1). The area was located in the arc of deforestation, a transitional area between the Savannah (Cerrado) and Amazon biomes, where increasing human occupation resulted in a mosaic landscape of agricultural farms and forest fragments of various sizes along the southern frontier of the Amazon Basin (Morton et al. 2006). Cantão State Park $\left(09^{\circ} 36^{\prime} \mathrm{S}, 50^{\circ} 03^{\prime} \mathrm{W}\right)$ was an 89,000 -ha protected area situated in Tocantins State. Vegetation was composed of semideciduous seasonal tropical forest with small grassland patches and it undergoes partial flooding during the wet season from September to March. With an annual average precipitation of $1,710 \mathrm{~mm} /$ year, water abundance varied cyclically due to the extensive network of rivers, canals, and lakes, presenting a seasonal 4-m oscillation of river level (Santa Fé Ranch staff, unpublished data). Consequently, flooding conditions influenced available resources (food and shelter) for fauna both spatially and temporally. The Santa Fé Ranch $\left(09^{\circ} 34^{\prime} \mathrm{S}, 50^{\circ} 21^{\prime} \mathrm{W}\right)$ was a 65,000-ha beef cattle ranch situated on the directly opposite bank of the Araguaia River, in southeastern Pará state. Around $65 \%$ of the ranch was covered by continuous secondary growth tropical rainforest, which stretched past the farm boundaries, whereas pastures occupied the other $35 \%$.

\section{METHODS}

Our research was part of a long-term jaguar and puma population monitoring program in the middle Araguaia River basin and, therefore, we designed camera-trap sampling to evaluate population density of these carnivores and abundance of their prey species.

We conducted 5 camera-trap surveys between July 2005 and November 2007, during both dry (3 sampling occasions) 
Table 1. Variables we used for modeling puma occupancy $(\psi)$ and detection probability $(\rho)$ in central Brazil, 2005-2007.

\begin{tabular}{|c|c|c|c|c|c|}
\hline \multirow[b]{2}{*}{ Variable name (abbreviation) } & \multirow[b]{2}{*}{ Description } & \multicolumn{4}{|c|}{ Categories } \\
\hline & & Sampling & Food & Human disturbance & Jaguar \\
\hline Area (area) & $\mathrm{SRF}^{\mathrm{a}}, \mathrm{CSP}^{\mathrm{b}}$ & $\mathrm{X}$ & & $\mathrm{X}$ & \\
\hline Year (yr) & $2005,2006,2007$ & $\mathrm{X}$ & & & \\
\hline Type of trail (type_trail) & Road, trail & $\mathrm{X}$ & & & \\
\hline Distance to road (dist_road) & Min. distance to road (m) & & & $\mathrm{X}$ & \\
\hline Distance to pasture (dist_past) & Min. distance to pasture (m) & & $\mathrm{X}$ & $\mathrm{X}$ & \\
\hline Distance to river (dist_river) & Min. distance to river $(\mathrm{m})$ & & & $\mathrm{X}$ & \\
\hline Distance to water source (dist_water) & Min. distance to closest water source (m) & & $\mathrm{X}$ & & \\
\hline Index of prey biomass (prey_bioms) & $\mathrm{BAI}^{\mathrm{c}}$ index of prey species detected & & $\mathrm{X}$ & & \\
\hline Richness of prey species (rich.prey) & No. of prey species detected & & $\mathrm{X}$ & & \\
\hline Richness of species (rich.spe) & No. of species detected & & $\mathrm{X}$ & & \\
\hline Jaguar presence (jaguar.pres) & Presence, absence of jaguar photos & & & & $\mathrm{X}$ \\
\hline Jaguar abundance (jaguar.rai) & No. of jaguar photos & & & & $\mathrm{X}$ \\
\hline
\end{tabular}

and wet seasons ( 2 sampling occasions). We set from 10 to 22 stations spaced 1-3 $\mathrm{km}$ apart throughout the area (Rabinowitz and Nottingham 1986, Karanth and Nichols 2002, Silver et al. 2004). Each station consisted of one passive infrared camera set on dirt roads or trails (animal- or human-made), placed approximately $50-70 \mathrm{~cm}$ above ground, except during the 2007 dry season at SFR where we set 2 cameras facing each other at each station (Silver 2004). We used 2 camera types: the Camtrakker (Cam Trakker, Watkinsville, GA) and the C1-BU (Vibrashine Inc., Taylorsville, MS). We programmed each camera to take photographs 24 hours/day with a 5-minute interval between consecutive photos. During surveys, we regularly (every 5-20 days) checked all stations to change film and batteries.

We analyzed individual photographs for species identification, number of individuals, sex, age (ad, subad, juv, or cub), date, and time. We considered each photo an independent event if one of the 3 following criteria was met: 1 ) consecutive photographs of different individuals of the same or different species, 2) consecutive photographs of conspecific individuals taken $>1$ hour apart, 3) nonconsecutive photos of individuals of the same species (O'Brien et al. 2003).

For each camera location we determined the relative abundance index (RAI) for all species, including puma and other sympatric carnivores (e.g., jaguar), that is

$$
\mathrm{RAI}_{i}=\left(g_{i} \Sigma_{j} \mathrm{p}_{i j} / \Sigma_{j} t n_{j}\right) \times 100
$$

where $g_{i}$ is an average group size for $i$ th species, $\mathrm{p}_{i j}$ is the number of independent "detections" for $i$ th species at $j$ th trap location, and $t n_{j}$ is the total trap-nights at the $j$ th trap location (O'Brien et al. 2003, Kawanishi and Sunquist 2004). We multiplied RAI by mean weight for each species according to data available in the literature (Sick 1997, IUCN et al. 2008) to produce a relative biomass abundance index (BAI) for each camera location. We also determined species richness as number of species detected for each camera station. We compared annual and seasonal capture rates using $\mathrm{R}$ ( $\mathrm{R}$ Version 8.2, <www.r-project.org>, accessed 20 Dec 2008).

\section{Puma Occupancy Models}

We categorized each trap site according to several numerical and categorical variables (Table 1). We did not evaluate vegetation variables due to macro-scale homogeneity within each of the 2 studied areas (SFR, CSP). We standardized all continuous covariates to $z$-scores prior to analysis, allowing model coefficients to be interpreted as the change in the logodds ratio of occupancy relative to a 1-standard deviation change in the covariate from its mean (Cooch and White 2005). We estimated puma occupancy $(\psi)$ and capture probability $(\rho)$ using a likelihood-based method (MacKenzie et al. 2002). We constructed detection histories (H) of pumas for each camera-trap location (site) over consecutive 7-day sampling occasions using a standard Xmatrix format (Otis et al. 1978). Therefore, for each site and each occasion, 1 indicated detection (photograph) of pumas, whereas 0 indicated nondetection. We obtained probability of detecting a puma during the 7-day period given their occupancy at a site from their detection histories. For example, a detection history for site $i\left(\mathrm{H}_{i}\right)$ of 11010 represented puma detections on the first, second, and fourth occasions over one season and a detection probability of

$$
\operatorname{Pr}\left(\mathrm{H}_{i}=11010\right)=\psi \rho 1 \rho 2(1-\rho 3) \rho 4(1-\rho 5)
$$

were $\rho i$ is capture probability in sampling occasion $i$.

We used Program PRESENCE (PRESENCE Version 2, $<$ http://www.proteus.co.nz>, accessed 15 Mar 2009) for defining puma detection probability and occupancy with the single-species single-season option (MacKenzie et al. 2006). This occupancy model (MacKenzie et al. 2006) uses multiple surveys on a collection of survey sites to construct a likelihood estimate using a series of probabilistic arguments. We can correct false negative surveys by estimating probability of detection, providing a more precise assessment of site occupancy values.

We used a 2-step approach to analyze data. First, we assessed the effect of sampling variables (Table 1) on detection probabilities, while keeping site occupancy constant (i.e., $\psi[.] \rho$ [variable]). Study area, year, camera placement, and prey diversity could play a crucial role in 
actual species occupancy of a given study site and, thus, we included these variables in our models. Second, we used the best-fitting model for detection probabilities and combined it with the candidate models representing biological hypotheses about puma occupancy (Burnham and Anderson 2002). We designed the models assuming 4 general hypotheses: 1) pumas mainly require a sufficient to high prey availability (Laundré et al. 2007), 2) human disturbance factors are the main determinants of presence and abundance (Haines 2006), 3) jaguar presence can influence puma occupancy (Scognamillo et al. 2003, Moreno et al. 2006), and 4) puma occupancy is affected by a combination of both anthropogenic and environmental factors (Haines 2006). We standardized effort for each camera location by considering only the first 42 days of trapping in the occupancy analysis, thus providing 6 7-day trapping occasions.

We used Akaike's Information Criterion corrected for small sample size ( $\mathrm{AIC}_{c}$; Akaike 1973) to identify the most parsimonious model for our data set. We used Akaike's weights $\left(w_{i}\right)$ to interpret the relative importance of each model's independent variables (Burnham and Anderson, 2002). Unless one model had a $w_{i} \geq 0.95$, we considered other models when drawing inferences about the data (Burnham and Anderson 2002).

\section{Individual Identification, Density Estimate, and Activity Pattern}

We used data collected from the 2-camera stations set between September and November 2007 in SFR to determine puma density, following a well-established camera-trapping protocol and capture-recapture analysis (Karanth and Nichols 1998, Moruzzi et al. 2002, Jackson et al. 2006, Kelly et al. 2008, Rowcliffe and Carbone 2008). We set 21 sampling stations on dirt roads and human-made trails throughout the 80-day survey period (Fig. 1).

Sampling for density estimates was guided by 2 critical premises (Karanth and Nichols 1998): 1) the population of the target species is closed (no gains or losses during sampling); and 2) all animals inhabiting the study area have a probability $>0$ of detection. We achieved the first premise by an adequate sampling period, which according to similar research on other large cat species (e.g., tiger [Panthera tigris] and jaguar) should not be $>2-3$ months (Karanth and Nichols 1998, Silver et al. 2004). We accomplished the second premise by placing cameras at a distance of no more than the diameter of a circle enclosing the smallest home range described for the species in the study area (Fig. 1), which assures a continuous sampling area and, thus, every puma has a nonzero probability of being photographed during sampling (Karanth 1995). Due to the lack of information on puma home range in our study area, we followed a protocol from similar studies and for similar species (Silveira 2004, Kelly et al. 2008).

Using the date and time of each photograph we described the activity pattern of pumas in the rainforest. We used a chi-square test to investigate whether pumas were more diurnal (0600-1759 hr) or nocturnal (1800-0559 hr). We set camera stations on 2 types of dirt roads, high-use (roads used weekly by people) and low-use (roads used no more than once per month), and 4 human-made trails established 2 months before sampling. We used a chi-square test to determine whether pumas used particular types of trail or roads according to their availability. We used Ivlev's Selectivity Index (SI) to evaluate puma selectivity toward different types of trails or roads: $\mathrm{SI}=\left(\mathrm{r}_{i}-\mathrm{p}_{i}\right) /\left(\mathrm{r}_{i}+\mathrm{p}_{i}\right)$, where $\mathrm{r}_{i}=$ proportion of photos in trail or road type $i$, and $\mathrm{p}_{i}$ $=$ proportion of trail or road type $i$ availability. Values of Ivlev's Index range from -1 (complete avoidance) to +1 (exclusive selection; Manly et al. 2002).

We based individual identification of pumas on 2 types of physical parameters: 1) time-stable parameters (SP), and 2) time-variable parameters (VP; Fig. 2). We classified SP as physical features that do not change over time (e.g., kinked tail, tail tip coloration, undercoat spot patterns, and coloration on the underside of legs; Kelly et al. 2008). Variable parameters consisted of marks that could vary with time, such as scars and botfly marks. The identification process included the following items (adapted from Jackson et al. 2006): 1) initial capture, a photograph that we could not positively match to a previously photographed puma; 2) recapture, a photograph that we could positively match to a previously identified animal; 3) null capture, a photograph that we could not identify as an initial capture or recapture; 4) primary features, the most distinctive features (body areas) and, therefore, the most useful for identification, for each photograph; 5) secondary features, all useful marks other than primary features; and 6) initial capture or recapture determination, positive identification by comparison of the primary feature in each photograph and $\geq 2$ other secondary features.

We pooled information from both cameras, ordered photographs chronologically, and for each flank we mapped all SPs to do a preliminary arrangement of individuals. Then we identified all VPs for the first photograph of each preliminarily identified individual and repeated this procedure with subsequent photographs, listing new VP features as they appeared (see example on Fig. 2), which allowed us to generate SP and VP histories that we used for definitive individual identification (see example on Fig. 2).

We estimated puma abundance using Program CAPTURE (Rexstad and Burnham 1991), following procedures described by Otis et al. (1978), White et al. (1982), and Karanth and Nichols (1998). Program CAPTURE tests several models that differ in their assumed sources of variation in capture probability. The null model $\left(\mathrm{M}_{o}\right)$, which is the simplest, assumes no variation among individuals or over time. More complex models include 1) the heterogeneity model $\left.\left(M_{b}\right), 2\right)$ the time variation model $\left(M_{t}\right)$, and 3) the behavior model $\left(\mathrm{M}_{b}\right)$, plus 3 combinations of these models (time and behavior; heterogeneity and behavior; time, behavior, and heterogeneity). Program CAPTURE identifies the best-fitting model and then generates capture statistics for all adequately fitted models, along with a test of the population closure assumption. Within the 7-day period we generated a sufficient number of captures, thus 

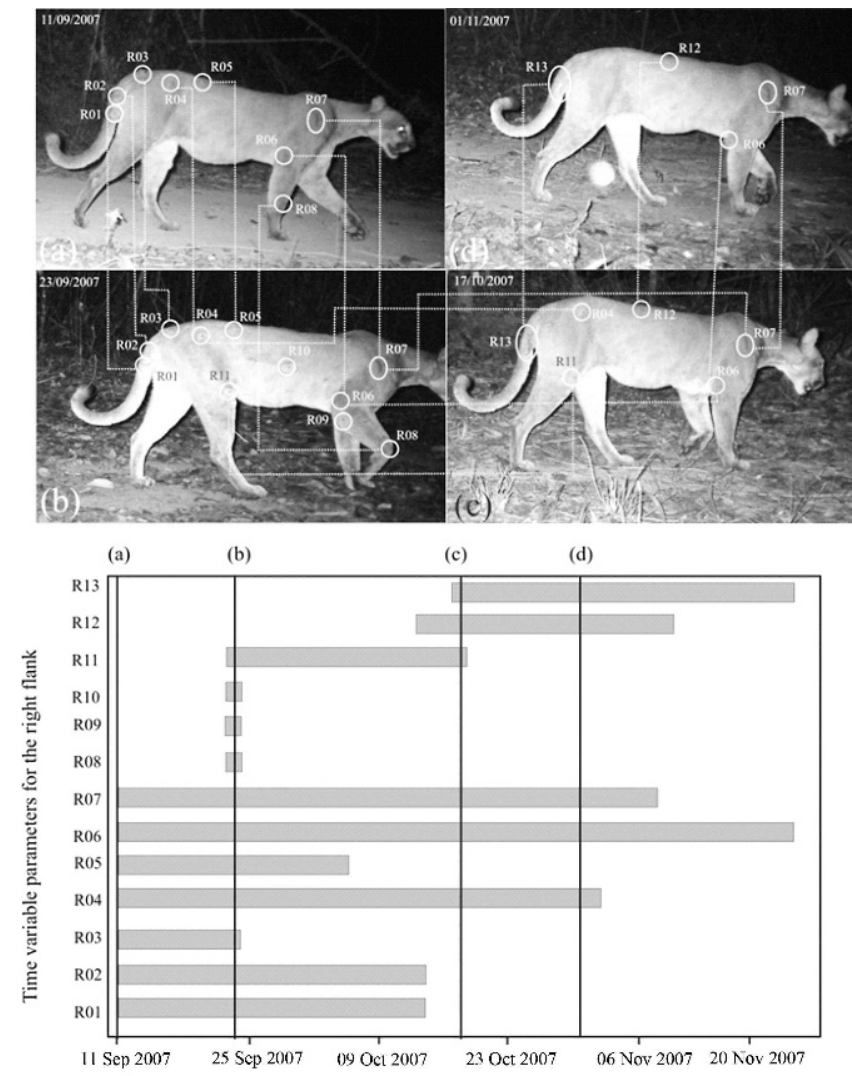

(e)

Figure 2. (a-d) Four (of 19) photographs we used to identify an adult puma in Santa Fé Ranch, Central Brazil, using camera-traps from the 2007 campaign. The images show the established time-variable parameters (VP) and their persistence among dates. (e) Time-variable parameters (VP) history chart. Bars represent persistence of VPs among photographs and (a), (b), (c), and (d) correspond to the photographs above.

maximizing the number of sampling occasions without violating population closure assumptions.

We considered 7 days of consecutive trapping as one sampling occasion and created a capture-recapture history for each puma identified within the survey. To determine the size of the sampled area, we used half of the mean maximum distance moved (half MMDM) between cameras by each recaptured puma as the buffer radius around each camera station (Silver et al. 2004; Fig. 1). Puma density D corresponded to the number of individuals determined by Program CAPTURE divided by the total surveyed area.

\section{RESULTS}

We recorded 101 puma captures over 7,929 camera-nights, representing an average capture success (RAI) of 1.27 captures/100 trap-nights, or one puma every 79 nights of trapping. We photographed pumas in $24.7 \%$ of all trapping stations. On average, we obtained $0.79(\mathrm{SE}=0.18$, range $=$ 0-12) captures/trap.

During dry seasons average puma RAIs at CSP were 0.06 $(\mathrm{SE}=0.06)$ for 2005 and $0.13(\mathrm{SE}=0.09)$ for 2006 (Table 2), whereas average RAI at SFR was higher (MannWhitney $U$-Test $W=331, P=0.013)$ ranging from 0.41 $(\mathrm{SE}=0.23)$ to $3.63(\mathrm{SE}=0.94)$. There was no significant difference in average puma RAI at SFR among sampling occasions, except when comparing 2006 and 2007 rainy season campaigns (Mann-Whitney $U$-Test $W=38, P=$ 0.017). Throughout all sampling campaigns $<10 \%$ of all camera stations in CSP and $>20 \%$ at SFR detected puma presence (Table 2).

We detected occurrence of another 45 medium-sized mammal and bird species. We were able to determine jaguar RAI, prey BAI, and prey richness (no. of species/camera station), which we incorporated in the following analyses.

We detected pumas at 39 sites (naïve site occupancy = $0.348, n=112$ ). Detection probability was best modeled with the linear effects of the covariates year, type of trail, and richness of prey species (rich.prey; $w_{i}=0.999, \Delta \mathrm{AIC}=$ $0)$, and so in subsequent analysis we used $\rho(\mathrm{yr}+$ type_trail + rich.prey; Table 3). Thus, we were more likely to detect pumas with cameras set on roads rather than on trails. The year of sampling was also positively correlated with puma detection probability $(P<0.05)$, as well as rich.prey $(P<$ $0.05)$. For candidate models, where $\psi$ varied with covariates, we found low support for the constant model, which had a low AIC weight $\left(w_{i}=0.000\right.$; Table 3$)$. Here, the most parsimonious model was $\psi$ (rich.prey + jaguar.rai) $\rho(y r+$ type_trail + rich.prey), which had a $w_{i}=0.991$ (Goodnessof-test of model $\chi^{2}=5.76, \mathrm{df}=6, P=0.067$ ) and was the only candidate model with a $\Delta$ AIC $\leq 2$ (Table 3 ). According to the most parsimonious model rich.prey had a positive influence on puma occupancy, with a $95 \%$ confidence interval not overlapping zero $(\psi=0.502$; $0.338-0.666$ ). The relationship between puma occupancy and jaguar RAI was also positive $(\psi=49.748 ; 27.183-$ 72.313, 95\% CI). Jaguar and puma RAI were correlated $(r=$ 0.721; $P<0.001)$.

\section{Identification of Puma Photographs}

According to patterns in SPs and VPs we were able to identify 8 individual pumas, 5 males, 2 females, and an individual of unknown gender (sex ratio 1:2.5). On average we recaptured each animal 2.17 times $(\mathrm{SE}=2.17$; range $=$ 0-19). We documented one female with a juvenile, thus confirming reproduction in the study area. Because juveniles likely have a capture probability different from that of adults (Karanth and Nichols 1998), we excluded the juvenile from subsequent analysis, and population estimates only refer to the adult puma population.

We set cameras to photograph the lateral view of individuals to detect the most diagnostic features. Consequently, most photographs showed $\geq 75 \%$ of the puma's torso and tail (75.6\%). We photographed $\geq 3$ limbs in $49.4 \%$ of samples, and in $25.0 \%$ of photos the puma's head was approximately perpendicular to the camera. Inadequate lighting, angle, or capture of only a part of the animal produced some poorquality photos, representing $12.8 \%$ of all photos.

For each photograph we identified an average of $1.12 \mathrm{SPs}$ $(\mathrm{SE}=0.07 ; n=75)$ and $4.36 \mathrm{VPs}(\mathrm{SE}=0.66 ; n=51)$ for the right flank and $3.64 \mathrm{VPs}(\mathrm{SE}=1.66 ; n=24)$ for the left flank. These identifications enabled us to generate $8 \mathrm{VP}$ histories for each flank, which corresponded to the 8 
Table 2. Camera-trapping campaign efforts and results for puma abundance estimates during 5 campaigns in Cantão State Park and Santa Fé Ranch in Central Brazil between 2005 and 2007.

\begin{tabular}{|c|c|c|c|c|c|c|c|c|}
\hline \multirow[b]{3}{*}{ Variable } & \multicolumn{3}{|c|}{ Cantão State Park } & \multicolumn{5}{|c|}{ Santa Fé Ranch } \\
\hline & \multirow{2}{*}{$\begin{array}{c}2005 \\
\text { Dry }\end{array}$} & \multicolumn{2}{|c|}{2006} & \multirow{2}{*}{$\begin{array}{c}2005 \\
\text { Dry }\end{array}$} & \multicolumn{2}{|c|}{2006} & \multicolumn{2}{|c|}{2007} \\
\hline & & Rainy & Dry & & Rainy & Dry & Rainy & Dry \\
\hline No. of trap stations & 21 & 10 & 22 & 12 & 14 & 17 & 11 & 21 \\
\hline $\begin{array}{l}\text { Total effort } \\
\quad(\text { camera-days) })^{a}\end{array}$ & 1,390 & 626 & 1,167 & 764 & 662 & 1,114 & 525 & 1,681 \\
\hline Mean no. of days ${ }^{b}$ & 66 & 63 & 53 & 64 & 47 & 66 & 48 & $\begin{array}{r}1,001 \\
80\end{array}$ \\
\hline $\mathrm{RAI}^{\mathrm{c}}$ & 0.059 & 0 & 0.130 & 0.413 & 0.837 & 0.985 & 3.625 & 3.464 \\
\hline$\pm \mathrm{SE}$ & 0.059 & 0 & 0.090 & 0.231 & 0.459 & 0.368 & 0.939 & 1.263 \\
\hline Min-Max RAI ${ }^{\mathrm{d}}$ & $0-1.235$ & $0-0$ & $0-1.429$ & $0-2.410$ & $0-4.545$ & $0-5.405$ & $0-7.500$ & $0-21.818$ \\
\hline Puma detection (\%) & 4.8 & 0 & 9.1 & 25.0 & 21.4 & 41.2 & 63.6 & 52.4 \\
\hline
\end{tabular}

${ }^{a}$ Total no. of days camera-trap sampling.

${ }^{\mathrm{b}}$ Mean no. of days with active stations.

${ }^{\mathrm{c}} \mathrm{RAI}=$ Relative Abundance Index.

${ }^{\mathrm{d}}$ Min. and max. puma RAI value for each sampling.

e $\%$ of camera stations with $\geq 1$ puma photo.

individuals we identified, combining information from both cameras (see example in Fig. 2). For the first photograph of each VP history we identified an average of 5.33 (SE = $0.31 ; n=8)$ parameters, although an average of only 0.33 $(\mathrm{SE}=1.60 ; n=8)$ VPs persisted on the last VP history photograph. The average number of persisting VPs from previous photographs was $3.73(\mathrm{SE}=1.21 ; n=66)$, which is clearly sufficient for an adequate identification using criteria by Jackson et al. (2006).

The heterogeneity model $\left(\mathrm{M}_{b}\right)$ was the most suitable model for the data and because it incorporated individual heterogeneity in capture probability, it could be considered an adequate reflection of the biological reality. Program CAPTURE did not indicate violation of the closed population assumption $(\mathrm{z}=-0.224 ; P=0.121)$ and estimated the population at 9 individuals ( $\mathrm{SE}=0.87,95 \%$ $\mathrm{CI}=8-10$ individuals) with a capture probability of 0.36 .

Recapture data from 6 individuals produced a MMDM of $8.4 \mathrm{~km}$ (range $=0-16.0)$ resulting in a buffer-strip width of $4.2 \mathrm{~km}$ (half MMDM). Consequently, effective area sampled was $264.7 \mathrm{~km}^{2}$ (Fig. 1) and puma density was estimated at $3.4(\mathrm{SE}=2.04)$ individuals $/ 100 \mathrm{~km}^{2}$.

Pumas showed nocturnal activity peaks at crepuscular hours and between 0000 hours and 0200 hours (Fig. 3). Pumas were more active at night than during the day $\left(\chi^{2}=\right.$ 14.02; $n=62 ; P<0.001)$. Pumas did not use roads and trails in proportion to their availability $\left(\chi^{2}=97.89 ; n=62\right.$; $P<0.001$; Fig. 4). Ivlev's Index indicated that puma selected positively low-use roads $(\mathrm{SI}=0.543)$ and high-use roads $(\mathrm{SI}=0.196)$ but avoided trails $(\mathrm{SI}=-0.893)$.

\section{DISCUSSION}

Our results emphasize that photographic capture-markrecapture sampling is a useful tool for estimating puma population size, as demonstrated by Kelly et al. (2008). Our method based on defined SPs and VPs proved to be practical and effective, allowing for identification on photographs of individuals that might have been inaccurately identified otherwise. Although we could not use SPs for all identifications, SPs can be useful for a preliminary assessment and for clarifying doubtful situations. We recommend 2 cameras placed on each side of potential movement paths, oriented at $45^{\circ}$ angles in relation to the path. This setup provides good-quality side-profile photographs of both flanks of the animal, which can be used to generate VP history charts. Although individual identification of pumas is more difficult than that of spotted or striped species, we found that use of camera-trapping practical and time-efficient (Karanth and Nichols 1998, Heilbrun et al. 2003, Jackson et al. 2006). Although conducting a blind identification test of puma photographs with participation of 3 investigators reached an average

Table 3. Best ranked site occupancy models from a second-step model-selection analysis for puma occupancy $(\psi)$ in central Brazil, using camera-trapping data obtained between 2005 and 2007, and computed by PRESENCE.

\begin{tabular}{|c|c|c|c|c|c|c|c|c|}
\hline Model $^{a}$ & $\mathrm{AIC}^{\mathrm{b}}$ & $\Delta \mathrm{AIC}^{\mathrm{c}}$ & $w_{i}^{\mathrm{d}}$ & $\begin{array}{c}\text { Model } \\
\text { likelihood }\end{array}$ & $\begin{array}{c}\text { No. of } \\
\text { parameters }\end{array}$ & $\begin{array}{c}-2 \times \\
\text { loglike }\end{array}$ & $\psi$ & SE $(\psi)$ \\
\hline $\begin{array}{l}\psi(\text { rich.prey }+ \text { jaguar.rai }) \\
\quad \rho(y r+\text { type_trail }+ \text { rich.prey })\end{array}$ & 424.82 & 0.00 & 0.991 & 1.000 & 7 & 410.82 & 0.388 & 0.093 \\
\hline$\psi($ jaguar.rai $), \rho(y r+$ type_trail + rich.prey $)$ & 434.89 & 10.07 & 0.006 & 0.007 & 6 & 422.89 & 0.386 & 0.094 \\
\hline$\psi($ rich.prey $), \rho(y r+$ type_trail + rich.prey $)$ & 436.51 & 11.69 & 0.003 & 0.003 & 6 & 424.51 & 0.365 & 0.099 \\
\hline$\psi(),. \rho(y r+$ type_trail + rich.prey $)$ & 449.59 & 24.77 & 0.000 & 0.000 & 5 & 439.59 & 0.347 & 0.102 \\
\hline
\end{tabular}

${ }^{a}$ The models are composed of both occupancy $(\psi)$ and detection $(\rho)$ covariates (variables description details in Table 1).

${ }^{\mathrm{b}} \mathrm{AIC}=$ Akaike's Information Criterion.

${ }^{\mathrm{c}} \triangle \mathrm{AIC}=$ relative difference of AIC values calculated comparing with smaller AIC value.

${ }^{\mathrm{d}} w_{i}=$ model wt calculated using the small sample version of AIC, indicating the relative support for a given model.

$\mathrm{e}-2 \times \log$ like $=$ twice the negative $\log$ likelihood. 


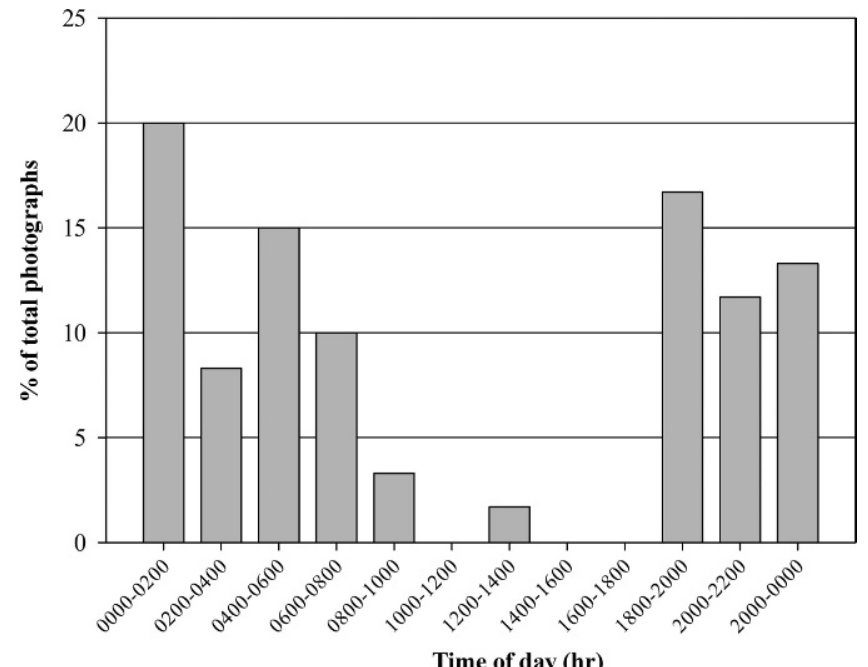

Time of day (hr)

Figure 3. Daily activity pattern of pumas in a forest area of Central Brazil obtained from camera-trapping history (2005-2007).

agreement on identification between pairs of investigators of nearly $80.0 \%$ and 3-way agreement of $72.9 \%$ (Kelly et al. 2008), we believe this process is much more time-consuming and consistent results can also be achieved with our approach. Using our protocol we expect that camera-trapping targeting other species (e.g., jaguar) can also produce data on puma density across its southern distribution range.

The selection of the heterogeneity model $\left(\mathrm{M}_{b}\right)$ by CAPTURE was supported by our data that revealed differences in capture probability among individuals and sexes, because 2 pumas accounted for $48 \%$ of all captures and males constituted the great majority of the detections. Consistent with our results, a photographic sex ratio skewed toward males has been observed for pumas (Kelly et al. 2008), tigers (Karanth and Nichols 1998, O'Brien et al. 2003), and jaguars (Silver et al. 2004). Also, probability of identifying an individual as being male is higher than that of identifying an individual as being female (most $\mathrm{F}$ would be included counted as nonsexed individuals) and, therefore, the biological relevance of these sex ratios is doubtful. The lack of information about territorial behavior and home range size for both sexes impairs further analysis.

Camera placement must be considered to reduce potential sources of bias in estimating puma abundance and occupancy, because the variable type of trail (road-trail) influenced detection probability. Furthermore, pumas avoided trails and selected low- and high-use roads, emphasizing the importance of camera placement to maximize capture probability, a prerequisite for reliable mark-recapture analysis (Karanth and Nichols 1998). Use of existing roads or of a permanent man-made large trail system, as opposed to the small trails we established in our study only shortly before commencing camera-trapping, seems essential when establishing a camera survey design (Dillon and Kelly 2007).

Some studies have shown that trap spacing (Dillon and Kelly 2007), small survey area (Maffei and Noss 2008), and the generalized use of half MMDM collected from camera-

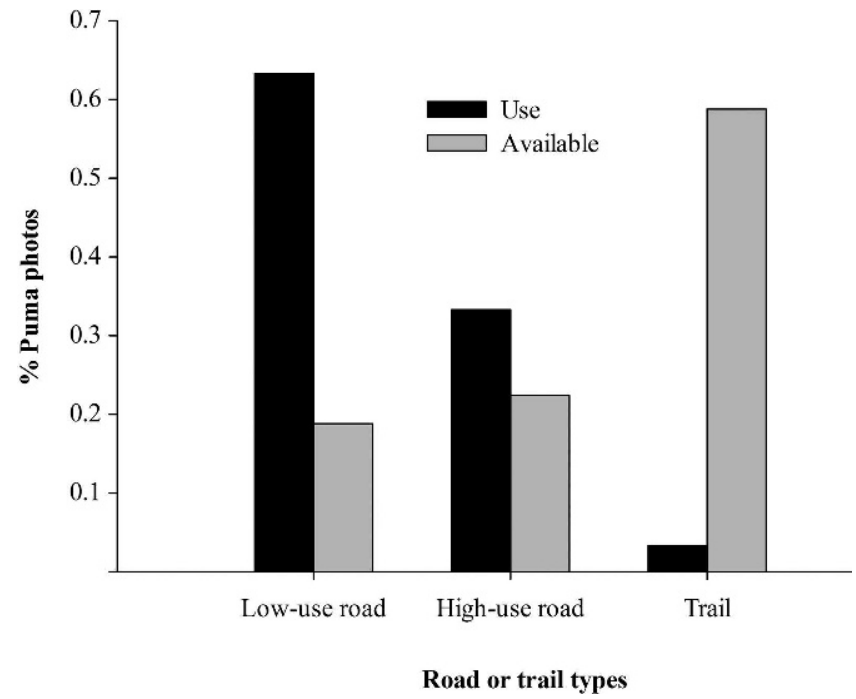

Figure 4. Percentage use of trail and road types by pumas in a forest area of Central Brazil from 5 camera-trapping campaigns (2005-2007).

traps (Soisalo and Cavalcanti 2006) can overestimate density by underestimating the effective area sampled. On the other hand, a recent study combining camera-trapping and radiotracking on leopard (Panthera pardus) favored the use of half MMDM for density estimation (Balme et al. 2009). Nevertheless, there is a consensus that camera distance and total sampled area should be based on the home range of the target species at the local study site. However, these data were not available for our study and we used recommendations for a similar species, the jaguar, and in doing so we believe we created a sampling scheme that allowed reasonable estimation of the parameters of interest.

Pumas in our study area presented a typical nocturnal behavior similar to that observed in North America (Waid 1990, McCain 2008, Sweanor et al. 2008), Peru (Emmons 1987), Venezuela (Scognamillo et al. 2003), and Brazil (Silveira 2004). Our density estimates (3.40 pumas $/ 100 \mathrm{~km}^{2}$ ) confirm the considerable variation of puma density along its geographic range. In North America, density is usually lower with $<1$ individual $/ 100 \mathrm{~km}^{2}$ (Hemker et al. 1984, Lindzey et al. 1994). In South America Kelly et al. (2008) reported densities of 5.13-8.01/100 $\mathrm{km}^{2}$ in Bolivia, 0.50$0.81 / 100 \mathrm{~km}^{2}$ in Argentina, and $2.35-4.91 / 100 \mathrm{~km}^{2}$ in Belize. Our results are in line with those obtained for Belize, which can be explained by habitat-level similarities (tropical forest with low understory cover; Kelly et al. 2008).

Puma RAI values increased throughout the years of sampling with a positive influence of sampling year on puma detection probability and occurrence in the area. Also, pumas seem to be present and more frequent in those places where cameras recorded higher species richness. The interaction of species richness with relative jaguar abundance is not clear, because the small data set precludes definitive conclusion. Other studies showed that puma and jaguar do coexist with segregation occurring at prey and habitat levels (Scognamillo et al. 2003, Novack et al. 2005). Our study area was located at the arc of deforestation, where habitat fragmentation, prey decline, and direct jaguar persecution 
may be altering jaguar and puma coexistence (Peres and Zimmerman 2001, Haines 2006).

The private forest reserve of the SFR presented a higher puma RAI compared to the SCP (Table 2). To compare capture rates as a measure of abundance between different areas, the species of interest must exhibit equal probability of detection. Although we employed a standard sampling design at both study sites, we acknowledge that microhabitat variables that we did not evaluate could have influenced detection probability and consequently bias the RAI (Harmsen et al. 2009). However, modeling showed that study area did not seem to have an effect on detection probability. The strong influence of flooding regime and consequent reduction of resource availability (prey and shelter) in CSP during the wet season suggests lower abundance and occupancy of puma and other animals in this area compared with the more stable environment at SFR, highlighting the importance of managing private land for conservation together with protected areas to create effective conservation networks for carnivores, particularly pumas (Beier 1993, Heines et al. 2006, Kautz et al. 2006, Wilson et al. 2006). Such conservation networks are of exceptional importance considering the increasing vulnerability of large felines in South America (Rabinowitz 1986, Nowell and Jackson 1996, Silveira and Jácomo 2002, Scognamillo et al. 2003).

\section{MANAGEMENT IMPLICATIONS}

The use of camera-trap surveys can produce valuable density estimates for pumas but requires proper camera placement and orientation to supply quality photos that allow unbiased identification. Along with adequate statistical models, this technique can also supply information on factors influencing species occupancy and help assess pumas' conservation status. We presented the first puma density estimate for the Amazon forest and our data highlight the importance of private forest reserves for large-felid conservation in the region. Nevertheless there is a paucity of information on forested environments in Central and South America, which impairs further comparisons of our estimates and, therefore, we strongly recommend further studies using reliable standardized protocols in the Neotropics.

\section{ACKNOWLEDGMENTS}

Our study was funded by Jaguar Conservation Fund, Ideawild, and Ecotropical Institute. N. Negrões was supported by a grant from Fundação para a Ciência e Tecnologia (FCT-MCT; SRFH/BD/23894/2005). We are indebted to Naturatins, CSP personnel, and SFR staff, especially to Marcos Mariani, for permission to work on his property and for logistic support. We thank C. Ferreira and 2 anonymous referees for comments on earlier versions of this manuscript.

\section{LITERATURE CITED}

Akaike, H. 1973. Information theory as an extension of the maximum likelihood principle. Pages 267-281 in B. N. Petrov and F. Csaki, editors. Second International Symposium on Information Theory, September 2001. Akademiai Kiado, Budapest, Hungary.
Balme, G. A., L. T. B. Hunter, and R. Slotow. 2009. Evaluating methods for counting cryptic carnivores. Journal of Wildlife Management 73:433441.

Beier, P. 1993. Determining minimum habitat areas and habitat corridors for cougars. Conservation Biology 7:94-108.

Burnham, K. P., and D. R. Anderson. 2002. Model selection and multimodel inference: a practical information-theoretic approach. Springer-Verlag, New York, New York, USA.

Carbone, C., S. Christie, K. Conforti, T. Coulson, N. Franklin, J. R. Ginsberg, M. Griffiths, J. Holden, K. Kawanishi, M. Kinnaird, R. Laidlaw, A. Lynam, D. W. Macdonald, D. Martyr, C. McDougal, L. Nath, T. O'Brien, J. Seidensticker, D. J. Smith, M. Sunquist, R. Tilson, and W. N. Shahruddin. 2001. The use of photographic rates to estimate densities of tigers and other cryptic mammals. Animal Conservation 4:75-79.

Cooch, E., and G. White. 2005. Program Mark: a gentle introduction. $<$ http://www.phidot.org/software/mark/docs/book>. Accessed $7 \mathrm{Jul}$ 2009.

Cutler, T. L., and D. E. Swann. 1999. Using remote photography in wildlife ecology: a review. Wildlife Society Bulletin 23:571-581.

Dillon, A., and M. J. Kelly. 2007. Ocelot Leopardus pardalis in Belize: the impact of trap spacing and distance moved on density estimates. Oryx 41:1-9.

Eisenberg, J. F. 1989. Mammals of the neotropics. Volume I. University of Chicago Press, Chicago, Illinois, USA.

Emmons, L. H. 1987. Comparative feeding ecology of felids in a neotropical rainforest. Behavioural Ecology and Sociobiology 20:271283.

Haines, A. M. 2006. Is there competition between sympatric jaguar Panthera onca and puma Puma concolor? Acta Zoologica Sinica 52:1421147.

Harmsen, B., R. J. Foster, S. Silver, L. Ostro, and P. Doncaster. 2009. Differential use of trails by forest mammals and the implications for camera-trap studies: a case study from Belize. Biotropica 42:126-133.

Heilbrun, R. D., N. J. Silvy, M. E. Tewes, and M. J. Peterson. 2003. Using automatically triggered cameras to individually identify bobcats. Wildlife Society Bulletin 31:748-755.

Heines, A. M., J. E. Janecka, M. E. Tewes, L. I. Grassman, Jr., and P. Morton. 2006. The importance of private lands for ocelot Leopardus pardalis conservation in the United States. Oryx 4:90-94.

Hemker, T. P., F. G. Lindzey, and B. B. Ackerman. 1984. Population characteristics and movement pattern of cougars in southern Utah. Journal of Wildlife Management 48:1275-1284.

International Union for Conservation of Nature [IUCN], Conservation International, Arizona State University, Texas A\&M University, University of Rome, University of Virginia, and Zoological Society London. 2008. An analysis of mammals on the 2008 IUCN Red List <www.iucnredlist.org/mammals>. Accessed 12 Dec 2008.

Jackson, R. M., J. Roe, R. Wangchuk, and D. Hunter. 2006. Surveying snow leopard populations with emphasis on camera trapping: a handbook. Snow Leopard Conservancy, Sonoma, California, USA.

Karanth, K. U. 1995. Estimating tiger (Panthera tigris) populations from camera-trap data using capture-recapture models. Biological Conservation 71:333-338.

Karanth, K. U., and J. D. Nichols.1998. Estimation of tiger densities in India using photographic captures and recaptures. Ecology 79:28522862.

Karanth, K. U., and J. D. Nichols. 2002. Monitoring tigers and their prey. A manual for researchers, managers and conservationists in Tropical Asia. Center for Wildlife Studies, Bangalore, India.

Kautz, R., R. Kawula, T. Hoctor, J. Comiskey, D. Jansen, D. Jennings, J. Kasbohm, F. Mazzotti, R. McBride, L. Richardson, and K. Root. 2006. How much is enough? Landscape-scale conservation for the Florida panther. Biological Conservation 130:118-133.

Kawanishi, K., and M. E. Sunquist. 2004. Conservation status of tigers in a primary rainforest of peninsular Malaysia. Biological Conservation 120:329-344.

Kelly, M. J., A. J. Noss, M. S. Bitetti, L. Maffei, and R. L. Arispe. 2008. Estimating puma density from camera trapping across three study sites: Bolivia, Argentina, and Belize. Journal of Mammalogy 89:408-418.

Laundré, J. W., L. Hernández, and S. G. Clark. 2007. Numerical and demographic responses of pumas to changes in prey abundance: testing current predictions. The Journal of Wildlife Management 71:345-355. 
Laundré, J. W., and J. Loxterman. 2007. Impact of edge habitat on summer home range size in female pumas. American Midland Naturalist $157: 221-229$

Lindzey, F. G., W. D. Van Sickle, B. B. Ackerman, D. Barnhust, T. P. Hemker, and S. P. Lang. 1994. Cougar population dynamics in southern Utah. Journal of Wildlife Management 58:619-624.

Logan, K. A., and L. L. Sweanor. 2001. Desert puma: evolutionary ecology and conservation of an enduring carnivore. Island Press, Washington, D.C., USA.

Machado, A. B. M., C. S. Martins, and G. M. Drummond. 2005. Lista da fauna brasileira ameaçada de extinção. Fundação Biodiversitas, Belo Horizonte, Brazil. [In Portuguese.]

MacKenzie, D. I., J. D. Nichols, G. B. Lachman, S. Droege, J. A. Royle, and C. A. Langtimm. 2002. Estimating site occupancy rates when detection probabilities are less than one. Ecology 83:2248-2255.

MacKenzie, D. I., J. A. Royle, J. D. Nichols, K. H. Pollock, L. L. Bailey, and J. E. Hines. 2006. Occupancy estimation and modelling: inferring patterns and dynamics of species occurrence. Academic, New York, New York, USA.

Maffei, L., and A. Noss. 2008. How small is too small? Camera trap survey areas and density estimates for ocelots in the Bolivian Chaco. Biotropica 40:71-75.

Manly, B. F. J., L. L. McDonald, D. L. Thomas, T. L. McDonald, and W. P. Erickson, 2002. Resource selection by animals: statistical design and analysis for field studies. Second edition. Kluwer Academic, London, United Kingdom.

McCain, E. B. 2008. Daily activity pattern of mountain lion (Puma concolor) in relation to the activity of their prey species in southern Arizona. Dissertation, Faculty of Humboldt State University, Humboldt, California, USA.

Moreno, R. S., R. W. Kays, and R. Samudio, Jr. 2006. Competitive release in diets of ocelot (Leopardus pardalis) and puma (Puma concolor) after jaguar (Panthera onca) decline. Journal of Mammalogy 87:808-816.

Morton, D. C., R. S. DeFries, Y. E. Shimabukuro, L. O. Anderson, E. Arai, F. Espirito-Santo, R. Freitas, and J. Morisette. 2006. Cropland expansion changes deforestation dynamics in the southern Brazilian Amazon. Proceedings of the National Academy of Sciences 103:1463714641.

Moruzzi, T., T. K. Fuller, R. M. DeGraaf, R. Brooks, and L. Wenjun. 2002. Assessing remotely triggered cameras for surveying carnivore distribution. Wildlife Society Bulletin 30:380-386.

Novack, A. J., M. B. Main, M. E. Sunquist, and R. F. Labisky. 2005. Foraging ecology of jaguar (Panthera onca) and puma (Puma concolor) in hunted and non-hunted sites within the Maya Biosphere Reserve, Guatemala. Journal of Zoology 267:167-178.

Nowell, K., and P. Jackson. 1996. Wild cats: status survey and conservation action plan. International Union for Nature Conservation (IUCN) /Cat Specialist Group, Gland, Switzerland.

O'Brien, T., M. F. Kinnard, and H. T. Wibisono. 2003. Crouching tigers, hidden prey: Sumatran tiger and prey populations in a tropical forest landscape. Animal Conservation 6:131-139.

Otis, D. L., K. P. Burnham, C. G. White, and D. R. Anderson. 1978. Statistical inference from capture data on closed animal's populations. Wildlife Monographs 62.

Pacheco, L. F., A. Lucero, and M. Villca. 2004. Dieta del puma (Puma concolor) en el Parque Nacional Sajama, Bolivia y su conflicto con la ganadería. Ecología en Bolivia 39:75-83. [In Spanish.]

Peres, C. A., and B. Zimmerman 2001. Perils in parks or parks in peril? Reconciling conservation in Amazonian reserves with and without use. Conservation Biology 15:793-797.
Rabinowitz, R. 1986. Jaguar predation on domestic livestock in Belize. Wildlife Society Bulletin 14:170-174.

Rabinowitz, A. R., and B. G. Nottigham, Jr. 1986. Ecology and behaviour of the jaguar (Panthera onca) in Belize, Central America. Journal of Zoology 210:149-159.

Redford, K. H., and J. F. Eisenberg. 1992. Mammals of the neotropics. Volume 2: the southern cone. University of Chicago Press, Chicago, Illinois, USA.

Rexstad, E., and K. P. Burnham. 1991. User's guide for Interactive Program CAPTURE. Colorado Cooperative Fish and Wildlife Research Unit, Colorado State University, Fort Collins, USA.

Rowcliffe, J. M., and C. Carbone. 2008. Surveys using camera traps: are we looking to a brighter future? Animal Conservation 11:185-186.

Scognamillo, D., I. Maxit, M. Sunquist, and J. Polisar. 2003. Coexistence of jaguar (Panthera onca) and puma (Puma concolor) in a mosaic landscape in the Venezuelan llanos. Journal of Zoology 259:269-279.

Sick, H. 1997. Ornitologia Brasileira. Editora Nova Fronteira, Rio de Janeiro, Brasil. [In Portuguese.]

Silveira, L. 2004. Ecologia comparada e conservação da onça-pintada (Panthera onca) e onça-parda (Puma concolor), no Cerrado e Pantanal Dissertation, University of Brasilia, Brasilia, Brazil. [In Portuguese.]

Silveira, L., and A. T. A. Jácomo. 2002. Conservación del jaguar en el centro del cerrado de Brasil. Pages 437-450 in A. B. Taber, C. B. Chetkiewicz, R. Medellín, A. Rabinowitz, and K. H. Redford, editors. El jaguar en el nuevo milenio. Fondo de Cultura Económica Universidad Nacional Autónoma de México and Wildlife Conservation Society, Distrito Federal, México. [In Spanish.]

Silveira, L., A. T. A. Jácomo, and J. A. F. Diniz-Filho. 2003. Camera trap, line transect census and track surveys: a comparative evaluation. Biological Conservation 114:351-355.

Silver, S. C. 2004. Assessing jaguar abundance using remotely triggered cameras. Wildlife Conservation Society, New York, New York, USA.

Silver, S. C., L. E. Ostro, L. K. Marsh, L. Maffei, A. J. Noss, M. J. Kelly, R. B. Wallace, H. Gómez, and G. Ayala. 2004. The use of camera traps for estimating jaguar Panthera onca abundance and density using capture/ recapture analysis. Oryx 38:148-154.

Soisalo, M. K., and S. M. C. Cavalcanti. 2006. Estimating the density of a jaguar population in the Brazilian Pantanal using camera-traps and capture-recapture sampling in combination with GPS radio-telemetry. Biological Conservation 129:487-496.

Sunquist, M., and F. Sunquist. 2002. Wild cats of the world. University of Chicago Press, Chicago, Illinois, USA.

Sweanor, L. L., K. A. Logan, J. W. Bauer, B. Millsap, and W. M. Boyce. 2008. Puma and human spatial and temporal use of a popular California State Park. Journal of Wildlife Management 72:1076-1084.

Trolle, M., and M. Kery. 2005. Camera-trap study of ocelot and other secretive mammals in the northern Pantanal. Mammalia 69:409-416.

Waid, D. D. 1990. Movements, food habits, and helminth parasites of mountain lions in southern Texas. Dissertation, Texas Tech University, Lubbock, USA.

White, G. C., D. R. Anderson, K. P. Burnham, and D. L. Otis. 1982 Capture-recapture and removal methods for sampling closed populations. Los Alamos, National Laboratory Publication LA-8787-NERP, Los Alamos, New Mexico, USA.

Wilson, S. M., M. J. Madel, D. M. Mattson, J. M. Grahamd, and T. Merrill. 2006. Landscape conditions predisposing grizzly bears to conflicts on private agricultural lands in the western USA. Biological Conservation 130:47-59.

Associated Editor: Gese. 